\title{
Factors affecting gestational length in the Mangalarga Paulista breed
}

\author{
J.R.M. Ferreira, M.G. Meirelles, C.F. Guimarães, M.A. Alonso, M. Nichi, C.B. Fernandes ${ }^{1}$
}

\begin{abstract}
Department of Animal Reproduction, School of Veterinary Medicine and Animal Sciences, University of São Paulo, São Paulo, SP, Brazil.
\end{abstract}

\begin{abstract}
The Mangalarga Paulista is a Brazilian horse breed that originated from a cross between Andalusian and Alter Real horses, and despite its national importance, no data exist regarding their gestational length. This study was conducted to determine the variation in gestation length and the influence of factors such as the sex of the foal, maternal age and parity, stallion and mating period. Retrospectively, data from 208 gestations of Mangalarga Paulista foals located in Piracaia, SP, Brazil, during the period from 1991 to 2012 were analyzed. The mean gestational length was $343.08 \pm 0.66$ days, with a range between 317 and 404 days. Gestation of mares carrying colts had a tendency to be longer than mares carrying fillies. Maternal parity significantly affected gestational length, with longer gestation for primiparous mares until the third gestation, shorter pregnancies between 4th and 8th gestation, and longer thereafter. Regarding mating period, mares that were mated at the end of the breeding season (January and February) had shorter pregnancies $(\mathrm{P}<0.05)$. These results are of significant clinical and economic relevance for the equine industry, so that the monitoring of gestation and parturition can be performed effectively.
\end{abstract}

Keywords: age, mare, parity, pregnancy.

\section{Introduction}

Mangalarga is a Brazilian breed originated from a cross between Andalusian and Alter Real horses, both of which are from the Iberian Peninsula and they were used with the intent of producing an animal suitable for work and sport. Other breeds were used for its final formation, including Thoroughbred, Arabian, Anglo-Arab and American Saddle Horse. The standard for the breed was only defined after 1934 with the founding of the Brazilian Mangalarga Breeders Association (Quadros et al., 2013).

Despite the national importance of the Mangalarga Paulista breed, there are no reports on the gestational length for this breed and the factors affecting it.

According to Macpherson and Paccamonti (2011), equine gestation ranges from 320 to 362 days, contradicting a concept that only fetuses with a gestational age of 330 days would be physiologically mature. For Koterba et al. (1990), gestation periods of less than 320 days or more than 365 days are considered abnormal, and these may result in the birth of immature or post-mature foals, respectively (Satué et al., 2011a).
However, shorter (Kurtz Filho et al., 1997) and longer (Walcovicz et al., 2013) gestational periods have been reported in the literature with normal foals born, showing a wide variation, which can impair predicting the date of parturition.

The estimation of gestational length is of great clinical and economic importance for the equine industry because it can be used to monitor foaling, thereby minimizing the risks to the mare and foal (Satué et al., 2011a). Another important aspect is the concern when pregnancy lasts more than 340 days, making owners and veterinarians cautious about the fetal and dam well-being, and this may lead to the equivocated decision of inducing parturition at the wrong moment and possibly the death of an immature foal.

In the literature, gestational length has been reported for Thoroughbred (Allen et al., 2002; Davies Morel et al., 2002; Duggan et al., 2008; Elliott et al., 2009), American Quarter Horse (QH; Duggan et al., 2008), Criollo (Winter et al., 2007), Pantaneiro Horse (Zuccari et al., 2002), Lusitano (Pérez et al., 2003; Valera et al., 2006) and Arabian (Valera et al., 2006) mares. In all of these studies, the mean gestational length ranged between 330 and 350 days (Satué et al., 2011a). It has been observed in Mangalarga Paulista breeding farms that their normal pregnancy is long, especially in primiparous mares. It is not uncommon to have mares with pregnancies longer than 365, resulting in healthy foals (Alonso; Santa Rita II Farm, Piracaia, SP, Brazil; personal communication).

Several factors may influence gestational length in horses and they can be environmental, maternal, fetal or related to the stallion; in addition, there is also individual variation. Recently, an interesting paper evaluated the influence of maternal lineage and they were able to detect a correlation between the mare's lineage and duration of pregnancy (Kuhl et al., 2015).

Thus, the aim of this study was to determine the variation in gestation length for the Mangalarga Paulista breed and evaluate the influence of the following factors: sex of the foal, maternal age and parity, stallion and mating period.

\section{Materials and Methods}

A retrospective study of data from 208 Mangalarga Paulista foals, born from 58 broodmares belonging to Santa Rita Farm II, located in Piracaia, São Paulo, Brazil (latitude 2303'14" South, longitude: 46 21'29" West, altitude: 792 meters) was conducted from 1991 to 2012. The factors that can influence gestational length analyzed were the sex of the foal, 
maternal age and parity, stallion effect and mating period.

Mares were kept in pasture under field condition, they grazed on Tifton grass and had free access to water and trace mineralized salt. During the last trimester of gestation, mares were fed $1 \mathrm{~kg}$ of a $15 \%$ crude protein concentrate. The parturitions were not monitored, but mares were checked at 11:00 PM at night and 6:00 AM the next day. Only normal foals with no signs of alterations or health issues at birth were considered.

The gestation length was calculated from the day of ovulation detected by palpation or ultrasonography evaluation until the time of foaling, as recommended in the literature (Satué et al., 2011a, b; Aoki et al., 2012). All data was collected from the breeding farm files.

Data were examined for normality using the Shapiro-Wilk test. Data that were not normally $(\mathrm{P}<0.05)$ distributed were transformed and reanalyzed. Data were analyzed by one-way ANOVA using the PROC GLIMMIX procedure (SAS, version 9.3; SAS Institute Inc., Cary, NC, USA). When a significant effect was observed, means were separated by the PDIFF option. Statistical differences were considered at $\mathrm{P} \leq 0.05$ and trends noted at $0.05 \leq \mathrm{P}<0.1$. Data are presented as the mean \pm SEM, unless otherwise indicated. Additionally, multiple regression was used to determine significant predictor variables for gestational length. Variables were selected by a stepwise elimination procedure.

\section{Results}

\section{Population study}

Of the 208 births analyzed, the mean gestation length of the Mangalarga breed was $343.08 \pm 0.66$ days, with a range between 317 and 404 days. Interestingly, $42.3 \%$ of all the pregnancies lasted 345 or longer.

The number of fillies born was 106, and their gestation length was $341.96 \pm 0.92$ days (range between 317 and 364), whereas for the 102 colts born, the mean gestation length was $344.32 \pm 0.93$ days (range between 323 and 404). This difference is not statistically significant $(\mathrm{P}=0.0736)$

\section{Mare age and parity}

Mare age ranged between 3 and 21 years and had no influence on the gestation length with mean \pm standard deviation of $343.73 \pm 10.41$ days. However, the analysis regarding parity from one to more than 10 times showed significant differences among groups as described in Table 1 .

Table 1. Mean and standard deviation of the gestation length for groups sorted according to the parity, collected from 208 Mangalarga mares between 1991 and 2012.

\begin{tabular}{|c|c|}
\hline 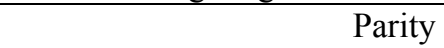 & Mean \pm SD gestation length \\
\hline G1 $(n=31)$ & $347.76 \pm 1.90^{\mathrm{A}}$ \\
\hline $\mathrm{G} 2(\mathrm{n}=32)$ & $345.15 \pm 2.32^{\mathrm{AB}}$ \\
\hline $\mathrm{G} 3(\mathrm{n}=23)$ & $345.82 \pm 3.38^{\mathrm{AB}}$ \\
\hline $\mathrm{G} 4(\mathrm{n}=21)$ & $341.08 \pm 1.75^{\mathrm{B}}$ \\
\hline G5 $(n=13)$ & $338.60 \pm 1.82^{\mathrm{B}}$ \\
\hline G6 $(n=11)$ & $337.67 \pm 2.75^{\mathrm{B}}$ \\
\hline $\mathrm{G} 7(\mathrm{n}=11)$ & $339.17 \pm 3.24^{\mathrm{B}}$ \\
\hline G8 $(n=7)$ & $342.86 \pm 3.20^{\mathrm{AB}}$ \\
\hline G9 $(n=3)$ & $343.33 \pm 3.71^{\mathrm{AB}}$ \\
\hline G10 $(n=6)$ & $343.40 \pm 6.31^{\mathrm{AB}}$ \\
\hline
\end{tabular}

G1: 1 birth; G2: 2 births; G3: 3 births; G4: 4 births; G5: 5 births; G6: 6 births; G7: 7 births; G8: 8 births; G9: 9 births; G10: $>10$ births. ${ }^{\mathrm{A}, \mathrm{B}}$ Different letters in the same column indicate significant difference $(\mathrm{P}<0.05)$.

\section{Stallion effect}

Six stallions were used between 1991 and 2012 and stallion effect was analyzed. No stallion effect on gestation length was found.

\section{Mating period}

Regarding the mating period, mares that were mated in August and October had the longest gestation period. In September there was a statistical difference from August, the duration of pregnancy reduced. November mated mares had gestations with the same duration as those bred in August, but longer than September. Mares mated in December showed a decrease in duration of pregnancy compared to October. Mares that were mated at the end of the breeding season (January and February), during the summer months, had shorter gestations compared to the other groups (Table 2). 
Table 2. Mean \pm standard error of the mean of the gestation length for the groups according to month of mating between 1991 and 2012.

\begin{tabular}{|c|c|}
\hline Mating period & Mean \pm SD \\
\hline August $(\mathrm{n}=8)$ & $349.86 \pm 4.52^{\mathrm{A}}$ \\
\hline September $(n=7)$ & $340.86 \pm 1.97^{\mathrm{BC}}$ \\
\hline October $(n=45)$ & $348.21 \pm 1.38^{\mathrm{A}}$ \\
\hline November $(n=68)$ & $344.38 \pm 1.14^{\mathrm{AB}}$ \\
\hline December $(n=40)$ & $342.58 \pm 1.46^{\mathrm{B}}$ \\
\hline January $(\mathrm{n}=19)$ & $336.33 \pm 1.46^{\mathrm{C}}$ \\
\hline February $(n=19)$ & $338.10 \pm 1.79^{C}$ \\
\hline
\end{tabular}

${ }_{A, B, C}$ Different letters in the same column indicate significant difference $(\mathrm{P}<0.05)$.

\section{Discussion}

The effect of breed on gestation length is important as a great variation can be found in the duration of pregnancy among different breeds, as reported by Allen et al. (2002), who also observed an effect of breed on the production of estrogens, progestogens and equine chorionic gonadotropin (eCG) in Thoroughbred-in-Thoroughbred, pony-in-pony, Thoroughbred-in-pony and pony-in-Thoroughbred gestations

The gestation length observed in the present study ( $343.08 \pm 0.66$ days) was greater than reported for the breeds Lusitano and Alter Real that were the ancestors of the Mangalarga breed. Valera et al. (2006) showed that the average gestation length in Spanish Andalusian mares is $336.8 \pm 0.48$ days. Carthusian mares raised in southern Spain have a gestation period of $338.95 \pm 9.55$ days (Pérez et al., 2003) and of 332.4 \pm 12.1 days (Satué et al., 2011b), all had shorter gestations than the average found in the present study. Likewise, Arabians had an average of $340.3 \pm 0.63$ days of gestation (Valera et al., 2006) and Thoroughbreds had mean gestation length of 334 days with a range of 315 to 360 days in mares housed in Paraná (Kurtz Filho et al., 1997). Allen et al. (2002), Davies Morel et al. (2002) and Galvin and Corley (2010) obtained a mean of $338 \pm 6.9,344.1 \pm 0.49$ and 340.03 days of gestation for Thoroughbred mares, respectively, with a minimum of 312 and a maximum of 383 days. McCue and Ferris (2012) found a gestation mean of $341 \pm 0.3$ days in Thoroughbreds and QHs. Even when comparing the same breeds, a wide variation in gestation length is found, as can be observed in the aforementioned studies. Some factors such as bloodlines in the same breed can affect the mean period of gestation, and also individual variation, management and climate. These can explain the longer gestation period found in the present study compared with the results in the literature.

In the present study, contrary to what is widely accepted, gender of the foal did not significantly influence the mean gestation length $(\mathrm{P}=0.074)$, which was $341.96 \pm 0.92$ days for fillies and $344.32 \pm 0.93$ days for colts. These results differ from the majority of data for different breeds, in which the gestation length for colts was longer than that for fillies (Bos and Van Der Mey, 1980; Davies Morel et al., 2002; Pérez et al., 2003; Valera et al., 2006; Satué et al., 2011a b; Aoki et al., 2012; McCue and Ferris, 2012). Only few publications were not able to detect a significant influence of gender on the length of gestation (Campitelli et al., 1982; Valente et al., 2006), as it was found in our study. As a tendency of longer gestation for colts $(P=0.074)$ was found, probably an increase in the number of observations could have been able to find an effect of gender.

A controversial aspect is the influence of age in gestational length. In the present study, an age effect was not observed, in agreement with several studies (Campitelli et al., 1982; Kurtz Filho et al., 1997, Galvin and Corley, 2010; Aoki et al., 2012; McCue and Ferris, 2012). However, Valera et al. (2006) concluded that as the mare ages, there is a rapid decrease in the gestation period until 10 to 12 years of life, with a subtle decrease after this age. Satué et al. (2011b) observed similar data, with mares between 8 and 12 years having shorter pregnancies (330.8 \pm 11 days) than those between 13 and 17 years $(336.1 \pm 8.9$ days $)$. It is important to note that age and parity are difficult factors to evaluate separately as primiparous mares are normally young and old mares are multiparous.

Regarding the effect of parity, primiparous mares had longer gestation than multiparous mares, with a mean of $347.76 \pm 1.90$ days for primiparous mares (Table 2), and these results corroborate those found by Pool-Anderson et al. (1994), Valente et al. (2006), Satué et al. (2011b) and Kuhl et al. (2015). According to Valera et al. (2006), the gestation length decreases until the fourth and fifth parity, then increases progressively in subsequent births. However, some authors were not able to find significant influence of parity on gestation length in draft mares (Aoki et al., 2012).

It has been suggested that primiparous mares, which are generally younger mares, are not anatomically and physiologically prepared compared to multiparous mares (Valera et al., 2006) as they did not have a prior gestation, therefore the contact area of fetus and placenta is smaller, resulting in a longer gestation. Wilsher and Allen (2003) demonstrated that foals born from primiparous mares were lighter than those born from multiparous mares, reinforcing the importance of the first pregnancy in uterine preparation so that, in subsequent pregnancies, the embryo encounters a more developed environment that is able to provide all of the potential to placental and fetal growth, thus possibly reducing the gestation length to the average duration in multiparous mares. As the mare ages, the uterus suffers from degeneration and it can diminish fetomaternal contact of placenta, thus it takes more time to fully 
develop the foal (Wilsher and Allen, 2003), and gestational length increases, as it was found in the present study after the 8th pregnancy.

Valera et al. (2006) and Aoki et al. (2012) observed a strong correlation between the length of a gestation in relation to the previous one in the same mare, and concluded that the individual factor is more influential than the sex of the foal. Thus, they proposed that it is useful to know about previous foaling from each mare for predicting the foaling date. On the other hand, in a herd of Warmblood mares in Germany, the previous gestational length did not help predicting the following, as mares with up to twelve foalings had an interval of 16 to 35 days in their pregnancy duration (Kuhl et al., 2015). When the multivariate regression was used, an effect of mare was not detected.

According to published data, the genetic makeup of the breed and the stallion could also influence the gestation length. Valera et al. (2006) found that the heritability for gestation length in Andalusian and Arabian animals is 0.21 , and the repeatability is 0.36 and 0.37 , respectively. Satué et al. (2011b) showed that some stallions tended to produce gestations that are shorter or longer than 340 days and therefore suggested that stallions that tend to prolong the gestation length should be used at the beginning of the breeding season. However, the present study did not find any influence of the stallion on the gestation length of Mangalarga Paulista mares.

The moment of conception proved an important factor, as it was found that when conception occurs at the end of the breeding season, there is a significant reduction in gestation length compared to mares bred at the beginning of the breeding season, thus confirming the findings of Campitelli et al. (1982), Macpherson and Paccamonti (2011) and Satué et al. (2011a). The authors of these studies suggest that the difference is most likely due to better nutritional and temperature conditions during the breeding season, in addition to the influence of sunlight on the endocrine system of the mare. Pérez et al. (2003) observed that gestation length decreases as the breeding season progresses, and it decreases 2.75 days for each month of delay in the mating of the mare. Satué et al. (2011b) also reported significantly shorter pregnancies in Carthusian mares mated between May and July (320.3 \pm 9.7 days) than those mated between November and January (333.2 \pm 13.6 days) and between February and April (335.6 \pm 10.0 days).

According to Kuhl et al. (2015), maternal lineage plays an important role in determining gestational length and the foal sex ratio, and they suggested that function differences might be the explanation for the difference. Another study that measured the percentage of mare and stallion influence on gestation duration found that 13 to $18 \%$ are related to the mare and only $2-3 \%$ to the stallion (Langlois and Blouin, 2012).

The gestation length in the Mangalarga Paulista breed, observed in this study, was of $343.08 \pm 0.66$ days, which is longer than the gestation lengths found for most breeds and closer to that recorded for
Thoroughbreds and QHs raised in the northern hemisphere. Also, gestational length with a difference of 87 days (317-404) resulted in viable and healthy foals, which is a wide variation, greater than previously reported for Warmblood mares, with almost two months of variation. Gestation length tended to be influenced by the sex of the foal. The factors that influenced the duration of pregnancy were parity and month of conception. It should be observed carefully that $42.3 \%$ of all pregnancies in the present study lasted 345 or longer, which is clinically important when we consider that most predictions of foaling are calculated using 330 days of duration. Even more interesting is that we had an incidence of $6.7 \%$ of gestations lasting more than 360 days, different from Valera et al. (2006) who reported less than $1 \%$ for Spanish breed and no occurrence for Arabians. Maybe this wider variation in Mangalarga might be due to the fact that it is a breed recently formed, and has the influence of several breeds and lineages in its formation. Owners and managers become extremely anxious and worried about the wellbeing of mare and foal, and knowing that Mangalarga's have longer gestation, this estimation can be more accurately performed.

These data show the wide variation in the gestation period of horses, and remarkably variable in Mangalarga Paulista breed, that confirms the clinical importance because a critical analysis when classifying a foal as premature, dysmature and post-mature should be done, as it could be noted that both a 317 and 404 pregnancy resulted in normal foals. Furthermore, monitoring gestation and time of parturition may prevent the loss of the mare and/or the foal in addition to minimizing economic losses.

\section{Acknowledgments}

The authors thank the financial support from CNPq (470664/2013-4) and Santa Rita II Farm (Piracaia, São Paulo, Brazil) for providing both the animals and the data used in this study.

\section{References}

Allen WR, Wilsher S, Stewart F, Stewart F, Ousey J, Ousey J, Fowden A. 2002. The influence of maternal size on placental, fetal and postnatal growth in the horse. II. Endocrinology of pregnancy. J Endocrinol, 172:237-246.

Aoki T, Yamakawa K, Ishii M. 2012. Factors affecting gestation length in heavy draft mares. J Equine Vet Sci, 33:437-440.

Bos H, Van Der Mey GJW. 1980. Length of gestation periods of horses and ponies belonging to different breeds. Livest Prod Sci, 7:181-187.

Campitelli S, Carenzi C, Verga M. 1982. Factors which influence parturition in the mare and development of the foal. Appl Anim Ethol, 9:7-14.

Davies Morel MCG, Newcombeb JR, Holland SJ. 2002. Factors affecting gestation length in the Thoroughbred mare. Anim Reprod Sci, 74:175-185.

Duggan VE, Holyoak GR, MacAllister CG, Cooper 
SR, Confer AW. 2008. Amyloid A in equine colostrum and early milk. Vet Immunol Immunopathol, 15:150155.

Elliott C, Morton J, Chopin. 2009. Factors affecting foal birth weight in Thoroughbred horses. Theriogenology, 71:683-689.

Galvin NP, Corley KTT. 2010. Causes of disease and death from birth to 12 months of age in the Thoroughbred horse in Ireland. Ir Vet J, 63:37-43.

Koterba AM, Drummond WH, Kosch PC. 1990 Equine Clinical Neonatology. Philadelphia, PA: Lea \& Febiger. pp. 55-65.

Kuhl J, Stock KF, Wulff M, Aurich C. 2015. Maternal lineage of Warmblood marescontributes to variation of gestational length and bias of foal sex ratio. PLoS One, 10:1-12.

Kurtz Filho M, Deprá NM, Alda JL, Castro IN, De la Corte FD, Silva JHS, Silva CAM. 1997. Duração da gestação em relação à idade de éguas da raça Puro Sangue de Corrida, aos pesos do potro e da placenta, e ao horário do parto. Braz J Vet Res Anim Sci, 34:37-40.

Langlois B., Blouin C. 2012. Genetic parameters for gestation length in French horse breeds. Livestock Science, 146: 133-139.

Macpherson ML, Paccamonti DL. 2011. Induction of parturition. In: McKinnon AO, Squires EL, Vaala WE, Varner DD (Ed.). Equine Reproduction. 2nd. Oxford, UK: Wiley-Blackwell. pp. 2262-2267.

McCue PM, Ferris RA. 2012. Parturition, dystocia and foal survival: a retrospective study of 1047 births. Equine Vet J, 44(suppl. 41):22-25.

Pérez CC, Rodríguez I, Mota J, Dorado J, Hidalgo M, Felipe M, Sanz J. 2003. Gestation length in Carthusian Spanishbred mares. Livest Prod Sci, 82:181187.

Pool-Anderson K, Raub RH, Warren JA. 1994.
Maternal influences on growth and development of fullsibling foals. J Anim Sci, 72:1661-1666.

Quadros JBS, Grasso PL, Seixas E. 2013. O que é. Associação Brasileira dos Criadores de Cavalo da Raça Mangalarga (ABCCRM) [Brazilian Mangalarga Breeder Association]. Available on: http://www.cavalomangalarga.com.br/mangalarga. Accessed on: Dec. 2013.

Satué K, Felipe M, Mota J, Muñoz A. 2011a. Factors influencing gestational length in mares: a review. Livest Prod Sci, 136:287-294.

Satué K, Felipe M, Mota J, Muñoz A. 2011b. Gestational length in Carthusian broodmares: effects of breeding season, foal gender, age of mare, year of parturition, parity and sire. Pol J Vet Sci, 14:173-180.

Valente M, Unanian MM, Villarroel ABS, Gomes

FFF. 2006. Duração da gestação e do parto em éguas Puro Sangue Árabe. Arq Bras Med Vet Zootec, 4:668671.

Valera M, Blesa F, Dos Santos, R.; Molina, A. 2006. Genetic study of gestation length in Andalusian and Arabian mares. Anim Reprod Sci, 95:75-96.

Walcowicz E, Unold O, Maciejewski H, Skrobanek P. 2014. The effect of selected factors on the length of gestation in Silesian mares. Animal Science Papers and Reports, 32: 55-64.

Wilsher S, Allen WR. 2003. The effects of maternal age and parity on placental and fetal development in the mare. Equine Vet J, 35:476-483.

Winter GHZ, Rubin MIB, De La Corte FD, Silva CAM. 2007. Gestational length and first postpartum ovulation of Criollo mares on a stud farm in Southern Brazil. J Equine Vet Sci, 27:531-534.

Zuccari CESN, Nunes DB, Correa Filho RAC. 2002. Reproductive eficiency in Pantaneira mares during breeding season 1995/2000. Arch Zootec, 51:139-148. 